Available online at GSC Online Press Directory

GSC Biological and Pharmaceutical Sciences

e-ISSN: 2581-3250, CODEN (USA): GBPSC2

Journal homepage: https://www.gsconlinepress.com/journals/gscbps

(RESEARCH ARTICLE)

\title{
Rutin and Vitamin E alleviate oxidative stress and hepatic-renal injury induced by technical and formulated Lambda-cyhalothrin in adult rats
}

\author{
Abbassy Moustafa Abdellatif*, Nasr Hoda M. and Mansy Awatef S. \\ Department of Plant Protection (Division of Pesticides Chemistry and Toxicology), Faculty of Agriculture, Damanhur \\ University. Damanhur, Egypt.
}

Publication history: Received on 26 June 2020; revised on 05 July 2020; accepted on 06 July 2020

Article DOI: https://doi.org/10.30574/gscbps.2020.12.1.0204

\begin{abstract}
Lambda-cyhalothrin (LCT) is a widely used pyrethroid to control insect pests in agriculture, public health and homes. The present study was designed to assess some of the toxicological effects in male rats following exposure to technical and formulated lambda-cyhalothrin (LCT T and LCT F.) and to evaluate the ameliorative effect of Vitamin E and Rutin administration. Nine groups of rats were designated for: control group; RT (50 mg kg-1 b.wt.); Vitamin E (100 mg kg-1 b.wt.); LCT T. (20 mg kg-1 b.wt); [LCT T. +Vitamin E]; [LCT T. +Rutin]; LCT F. (20 mg a.i. kg-1 b.wt); [(LCT F.) +Vitamin E] and [(LCT F.) +Rutin]. Results revealed that both of technical and formulated lambda-cyhalothrin treatments caused significant increase in LPO level and decrease in the activities of antioxidant enzymes: catalase, superoxide dismutase, glutathione-s-transferase Glutathione peroxidase, and glutathione reductase. Also, both forms of lambda-cyhalothrin caused significant increase in the activity of alanine and aspartate transaminases and alkaline phosphatase, lactate dehydrogenase and creatinine, uric acid levels, whereas albumin, total protein were decreased. Coadministration of Vit.E or Rutin achieved noticeable ameliorative effects. Thus, the overall results revealed the powerful ameliorating effect of Vit.E and Rutin in pyrethroids (e.g.LCT)-intoxicated rats.
\end{abstract}

Keywords: Lambda-cyhalothrin; Rutin; Vitamin E; Oxidative stress biomarkers; Rats.

\section{Introduction}

Pyrethroids are among the most widely used synthetic pesticides. Their widespread use has stimulated research into the possible existence of effects related with their oxidative stress and hepatic-renal toxicity in mammals. Their lipophilic nature facilitates bioaccumulation in membranes leading to the generation of reactive oxygen species (SOR) that elicits oxidative damage in mammals. Lambda-cyhalothrin (LCT), a synthetic Type II pyrethroid insecticide, is one of the commonly used insecticide for control of many insect pests. A few studies report the involvement of oxidative stress in pyrethroid-induced toxicity $[1 ; 2 ; 3 ; 4]$.

Antioxidants are defense against free radical and oxidative attacks. They act as free radical scavengers and slow down not only radical oxidation but also the accompanying damaging effects in the body [5]. Rutin (RT), a quercetin-3rutinosidand sophorin or vitamin-P, is a well-known flavonoid glycoside and set as an affective phenolic compound. Rutin has shown pharmacological benefits including anti-tumor [6] and hepatic protective activities [7]. It is an antioxidant, comprised of the flavonol quercetin and the disaccharide rutinose. RT has been demonstrated to scavenge superoxide radicals. Moreover, RT has inhibitory effects against membrane lipid peroxidation and generation of ROS [8].

Vitamin E (alpha-tocopherol) is a fat soluble vitamin which regulates different oxidation processes in the body as it acts as a powerful antioxidant. Previous studies revealed that dietary intake of vitamin $\mathrm{E}$ can normalize the damaging effect

\footnotetext{
* Corresponding author: Abbassy Moustafa Abdellatif
}

Copyright (C) 2020 Author(s) retain the copyright of this article. This article is published under the terms of the Creative Commons Attribution Liscense 4.0. 
of oxidative stress induced by oxygen free radicals $[9 ; 10 ; 11]$. Therefore, this study was designed to investigate the oxidative stress and hepatic-renal toxicity induced by lambda-cyhalothrin and to assess the ameliorative effect of Vit.E and RT supplementation in conjunction with each of technical and formulated lambda-cyhalothrin using male rats as test organism.

\section{Material and methods}

\subsection{Chemicals and reagents}

Lambda-cyhalothrin technical, LCT T., (>99\% pure) was obtained from Nanjing Panfeng Chem Ltd. (Nanjing, Jiangsu, China). Formulated Lambda-cyhalothrin, LCT F., (Trade name: Lambda EG ${ }^{\circledR} 5 \%$ EC) was purchased from Arab Company for Chemical Industries for Egyptian of Agricultural Development, Cairo. Egypt. Rutin were procured in their highest grades available from Sigma-Aldrich (St. Louis, MO, USA). Vitamin E manufactured by PHARCO pharmaceutical company, Kits of catalase (CAT), superoxide dismutase (SOD), glutathione-s-transferase (GST). Glutathione peroxidase (GPX), and glutathione reductase (GR) were obtained from Bio-diagnostic Company Dokki, Giza, Egypt. Other chemicals and reagents were all of analytical grade.

\subsection{Animals}

Male Albino rats (weighing 150-170g) were obtained from the animal house of the Faculty of Medicine, Alexandria University, Egypt. The local committee approved the design of the experiments, and the protocol conforms to the guidelines of the National Institutes of Health. Rats were caged in groups of eight, given food and water ad-libitum. The animal room was maintained at $\left(23 \pm 2{ }^{\circ} \mathrm{C}\right)$ and $40-60 \%$ relative humidity with 12 -h light-dark cycles, the light cycle coinciding with the day light hours. Rats were acclimatized for 2 weeks prior to the start of experiments. The experimental work on rats was performed with the approval of the Animal Care \& Experimental Committee, National Research Centre, Cairo, Egypt, and according to the guidance for care and use of laboratory animals [12].

\subsection{Experimental design}

The rats were divided into nine groups of eight animals each. Lambda- cyhalothrin technical or formulated (LCT T., LCT F.) was administered at a dose $20 \mathrm{mg}$ a.i. $\mathrm{kg}^{-1}$ b.wt, [13]; Rutin and Vit.E were administered at a dose 50 and $100 \mathrm{mg} \mathrm{kg-}$ 1 b.wt, respectively [14]. Animals were treated with the tested compounds by oral gavages day by day for 30 days. The first group (control), rats received by oral gavage corn oil $(0.5 \mathrm{ml} / \mathrm{rat})$. The second and third groups, rats received Vit.E (100 mg kg-1 b.wt.) and RT (50 mg kg-1 b.wt), respectively. The fourth group, rats received LCT T., $20 \mathrm{mg} / \mathrm{kg} \mathrm{b.wt.,}$ while the fifth and sixth groups, (LCT T. plus Vit.E) and (LCT T. plus RT), rats received the same treatments as did animals in the second; third and the fourth groups. The seventh group received LCT F., $20 \mathrm{mg}$ a.i./ $\mathrm{kg}$ b.wt., while the eighth and ninth groups (LCT F. plus Vit.E) and (LCT F. plus RT), rats received the same treatments as did animals in the second, third and seventh groups. Dosages of each administered material were freshly prepared and adjusted weekly for body weight changes and given at approximately the same time each morning.

\subsection{Blood collection}

The animals were starved overnight for $12 \mathrm{~h}$ before blood was collected. Rats were anaesthetized with light ether and venous blood samples were collected by direct heart puncture into sterilized vials and allowed to stand for 30 min at room temperature to clot before being centrifuged at $3000 \times \mathrm{g}$ for $15 \mathrm{~min}$. Serum was obtained by centrifugation and stored at $-60 \circ \mathrm{C}$. Serum samples were a liquated in Eppendorf tubes to use each one for one time.

\subsection{Biochemical analysis}

\subsubsection{Thiobarbituric acid-reactive substances (TBARS)}

Lipid peroxidation levels were measured by the thiobarbituric acid (TBA) reaction using the method of [15]. This method was used to measure spectrophotometrically the color produced by the reaction of TBA with malondialdehyde (MDA). $1.5 \mathrm{ml}$ of $0.8 \%$ thiobarbituric acid was added to $1 \mathrm{ml}$ of serum sample. Then $0.4 \mathrm{ml}$ of $8.1 \%$ sodium dodecyl sulfate and $1.5 \mathrm{ml}$ of acetic acid were added. The mixture was finally made up to $5 \mathrm{ml}$ with distilled water and placed in a hot water bath at $95^{\circ} \mathrm{C}$ for $1 \mathrm{~h}$. After cooling, $1.0 \mathrm{ml}$ of distilled water and $5 \mathrm{ml}$ of the mixture of $n$-butanol and pyridine $(15: 1, \mathrm{v} / \mathrm{v})$ were added. The mixture was vortexed and after centrifugation at $4000 \mathrm{rpm}$ for 10 min, the absorbance of the organic layer (upper layer) was measured by the spectrophotometer at $532 \mathrm{~nm}$ against blank using distilled water. Thiobarbituric acid when allowed to react with MDA aerobically formed a colored complex [MDA - (TBA) 2 complex] which was measured by the spectrophotometer. 


\subsubsection{Reduced glutathione (GSH)}

Was determined by the method of [16] .One ml of supernatant was taken and $0.5 \mathrm{ml}$ of Ellman's reagent $(0.0198 \%$ DTNB in $1 \%$ sodium citrate) and $3 \mathrm{ml}$ of phosphate buffer ( $\mathrm{pH} \mathrm{8.0)}$ was added. The color developed was read at $412 \mathrm{~nm}$.

\subsubsection{Superoxide dismutase activity (SOD; EC 1.15.1.1)}

Was determined spectrophotometrically according to [17]. The assay procedure involves the inhibition of epinephrine auto-oxidation in an alkaline medium to adrenochrome, which is markedly inhibited by the presence of SOD. Samples were added to reaction mixture made in sodium carbonate buffer, $\mathrm{pH}$ 10.2, the absorbance change was recorded at 480 $\mathrm{nm}$.

\subsubsection{Catalase (CAT; EC 1.11.1.6)}

Activity was determined according to the method of [18]. The method is based on the decomposition of H2O2 by catalase. The reaction mixture was composed of $50 \mathrm{mM}$ phosphate buffer of pH 7.0; $10 \mathrm{mM} \mathrm{H} 2 \mathrm{O} 2$ and erythrocyte lysate. The reduction rate of $\mathrm{H} 2 \mathrm{O} 2$ was followed at $240 \mathrm{~nm}$ for $30 \mathrm{~s}$.

\subsubsection{Glutathione peroxidase (GPx; EC 1.11.1.7)}

Determination was done according to the method of [19]. The assay is an indirect measure of the activity of c-GPx. Oxidized glutathione (GSSG), produced upon reduction of organic peroxide by c-GPx, and is recycled to its reduced state by the enzyme glutathione reductase (GR), The oxidation of NADPH to NADP+ is accompanied by a decrease in absorbance at $340 \mathrm{~nm}\left(\mathrm{~A}_{340}\right)$ providing a spectrophotometric means for monitoring GPx enzyme activity.

\subsubsection{Glutathione S-transferase (GST; EC 2.5.1.18)}

Activity was measured spectrophotometrically by the method of [20] using S-2, 4-dinitrophenyl glutathione (CDNB) as a substrate. The principle of the method is based on measurement of the conjugation of $S$-2, 4-dinitrophenyl glutathione (CDNB) with reduced glutathione. The formation of adduct of CDNB, S-2, 4-dinitrophenyl glutathione was monitored by measuring the net increase in absorbance at $340 \mathrm{~nm}$ against the blank.

\subsubsection{The glutathione reductase (GR; EC 1.6.4.2)}

Activity was estimated by measuring the change in absorbance at $340 \mathrm{~nm}$ due to NADH utilization and GR activity was expressed as $\mathrm{n}$ moles NADPH oxidized/min/mg proteins using an extinction coefficient of $6.22 \mathrm{mM}-1 \mathrm{~cm}-1$ [21].

\subsubsection{Alkaline phosphatase (ALP; EC 3.1.3.1)}

Activity was determined according to [22].

\subsubsection{Aspartate aminotransferase (AST; EC 2.6.1.1), alanine transaminase (ALT; EC 2.6.1.2)}

Activities were determined by colorimetric method according to [23].

\subsubsection{Lactate dehydrogenase (LDH; EC 1.1.1.27)}

Activity was determined was carried out according to the method of [24].

\subsubsection{Total Protein content}

Content of total protein was determined using the method described by [25]. Folin and Ciocalteus phenol reagent was used to develop the blue color that was measured spectrophotometrically at $750 \mathrm{~nm}$. Bovine serum albumin was used as a standard.

\subsubsection{Uric acid}

Uric acid was determined according to the method of [26].

\subsubsection{Creatinine}

Creatinine was determined according to the method of [27]. 


\subsection{Estimation of ameliorative effect of Vitamin $\mathbf{E}$ and Rutin}

The "Amelioration Index" (AI) could be estimated by comparing the results of a given biochemical parameter in the groups of pesticides + antioxidant agent (Vit.E or Rutin, RT) with the results of the control group to assess the ameliorative effect of Vit.E or RT. As "AI" approaches 1, the amelioration reaches a high degree of normalization to the control value [28]:

Amelioration index $(\mathrm{AI})=$ Treatment value $($ Pesticide $+\mathrm{Zn}) /$ Control value

\subsection{Statistical Analysis}

The results were expressed as means \pm S.E.M. All data were done with the Statistical Package for Social Sciences (SPSS 12.0 for windows). The results were analyzed using one way analysis of variance (ANOVA) followed by Duncan's test for comparison between different treatment groups. Statistical analysis was significance at $\mathrm{p} \leq 0.05$.

\section{Results}

\subsection{Effects of lambda-cyhalothrin on the activity of AST, ALT, ALP, LDH in serum of treated rats}

There was no significant changes in the activity of the biomarker enzymes ALT, AST, ALP and LDH in the serum of Rutin - or Vit E - treated rats compared to control, while $\lambda$-Cyhalothrin- (LCT T., LCT F.) treated rats showed significant increase $(\mathrm{P} \leq 0.05)$ in these biomarkers, indicating the occurrence of hepatic injury (Table1).However, co-treatment with Vit.E or RT restored the levels of these biomarkers in the combined groups [(LCT.T) + Vit.E, , [(LCT.T) + RT], [(LCT.F) + Vit.E] and [(LCT.F) + RT] back to normal control. Thus, the activity of such antioxidants, Vit E or Rutin, to decrease the hepatotoxicity signs resulted from $\lambda$-Cyhalothrin was significantly $(\mathrm{P} \leq 0.05)$ observed.

Table 1 Activities of some biomarkers related to hepatotoxicity in serum of male rats induced by lambda-cyhalothrin (LCT T.; LCT F.) and the ameliorative effect of Vit. E and RT supplementation.

\begin{tabular}{|c|c|c|c|c|c|c|c|c|}
\hline & AST (U/L) & & $\operatorname{ALT}(U / L)$ & & $\operatorname{ALP}(U / L)$ & & LDH (U/L) & \\
\hline Treatments & Mean \pm SE & A.I. & Mean \pm SE & A.I. & Mean \pm SE & A.I. & Mean \pm SE & A.I. \\
\hline Control & $36.71 \pm 0.305^{\mathrm{k}}$ & - & $31.39 \pm 0.255^{\mathrm{k}}$ & - & $106.23 \pm 1.58^{f}$ & - & $162.47 \pm 1.23^{\mathrm{gh}}$ & - \\
\hline Vitamin (E) & $36.59 \pm 0.413^{\mathrm{k}}$ & - & $30.96 \pm 0.306^{\mathrm{k}}$ & - & $104.66 \pm 0.98^{f}$ & - & $163.89 \pm 1.66^{\mathrm{fgh}}$ & - \\
\hline RT & $37.15 \pm 0.054 \mathrm{jk}$ & - & $32.38 \pm 0.231^{j}$ & - & $107.48 \pm 1.76^{\mathrm{f}}$ & - & $161.82 \pm 3.37 \mathrm{~h}$ & - \\
\hline (LCT T.) & $51.45 \pm 0.266^{\mathrm{d}}$ & - & $62.41 \pm 0.189 b$ & - & $138.03 \pm 1.69^{c}$ & - & $201.51 \pm 1.95^{c}$ & - \\
\hline (LCT T.) + Vit.E & $40.07 \pm 0.150^{h}$ & 1.08 & $42.33 \pm 0.273 \mathrm{ghi}$ & 1.34 & $104.13 \pm 1.02^{\mathrm{f}}$ & 0.98 & $169.84 \pm 1.24 \mathrm{efg}$ & 1.04 \\
\hline (LCT T.) + RT & $37.26 \pm 0.097 \mathrm{jk}$ & 1.01 & $46.06 \pm 0.220^{\mathrm{e}}$ & 1.46 & $117.25 \pm 1.33^{\mathrm{e}}$ & 1.10 & $170.18 \pm 1.37^{\mathrm{efg}}$ & 1.05 \\
\hline (LCT F.) & $53.29 \pm 0.338^{c}$ & - & $63.36 \pm 0.321^{\mathrm{a}}$ & - & $145.22 \pm 2.34^{b}$ & - & $209.38 \pm 2.03^{b}$ & - \\
\hline (LCT F.) + Vit.E & $41.70 \pm 0.171^{\mathrm{fg}}$ & 1.13 & $42.93 \pm 0.256^{\mathrm{fgh}}$ & 1.36 & $107.90 \pm 1.04^{\mathrm{f}}$ & 1.01 & $178.33 \pm 0.89 \mathrm{~d}$ & 1.09 \\
\hline (LCT F.) + RT & $37.95 \pm 0.209^{i j}$ & 1.03 & $43.77 \pm 0.178^{f}$ & 1.39 & $120.32 \pm 1.13^{\mathrm{e}}$ & 1.13 & $169.19 \pm 1.23^{\mathrm{efg}}$ & 1.04 \\
\hline
\end{tabular}

\subsection{Effects of LCT on albumin, total protein, creatinine and uric acid in serum of treated rats}

In comparison to control group, Vit.E or RT-treated rats showed non-significant changes in serum albumin, total protein, creatinine and uric acid, while in LCT-treated rats showed a significant increase in serum uric acid and creatinine with a significant $(\mathrm{P} \leq 0.05)$ decrease in the total protein, and albumin levels. Co- administration of Vit.E or RT with $\lambda$ Cyhalothrin preserve the levels of albumin, total protein, creatinine and uric acid near normal level. Thus, coadministration of Vit E or RT to the $\lambda$-Cyhalothrin treated-rats resulted in a significant recovery in the above mentioned parameters to those in control rats (Table 2). 
Table 2 Levels of some biomarkers related to nephrotoxicity in serum of male rats induced by lambda-cyhalothrin (LCT T. and LCT F.) and the ameliorative effect of Vit.E and RT supplementation.

\begin{tabular}{|c|c|c|c|c|c|c|c|c|}
\hline \multirow[t]{2}{*}{ Treatments } & \multicolumn{2}{|l|}{$\begin{array}{l}\text { Albumin } \\
\text { (g/dl) }\end{array}$} & \multicolumn{2}{|c|}{ Total protein $(\mathrm{g} / \mathrm{dl})$} & \multicolumn{2}{|l|}{$\begin{array}{l}\text { Creatinine } \\
\text { (mg/dl) }\end{array}$} & \multicolumn{2}{|l|}{$\begin{array}{l}\text { Uric Acid } \\
(\mathrm{mg} / \mathrm{dl})\end{array}$} \\
\hline & Mean \pm SE & A.I.* & Mean \pm SE & A.I.* & Mean \pm SE & A.I.* & Mean \pm SE & A.I.* \\
\hline Control & $4.73 \pm 0.075^{b}$ & - & $8.54 \pm 0.133^{a}$ & - & $0.74 \pm 0.005^{\mathrm{k}}$ & - & $5.68 \pm 0.092^{c}$ & - \\
\hline Vitamin $(E)$ & $4.71 \pm 0.08^{b}$ & - & $8.61 \pm 0.190^{\mathrm{a}}$ & - & $0.73 \pm 0.011^{\mathrm{k}}$ & - & $5.62 \pm 0.136^{c}$ & - \\
\hline RT & $4.75 \pm 0.0 .68^{b}$ & - & $8.51 \pm 0.248^{a}$ & - & $0.77 \pm 0.017^{\mathrm{k}}$ & - & $5.76 \pm 0.112^{c}$ & - \\
\hline (LCT T.) & $4.25 \pm 0.030^{\mathrm{d}}$ & - & $5.98 \pm 0.178^{d}$ & - & $1.08 \pm 0.011 \mathrm{~g}$ & - & $8.05 \pm 0.112^{\mathrm{a}}$ & - \\
\hline (LCT T.) + Vit.E & $4.49 \pm 0.032^{c}$ & 0.95 & $7.85 \pm 0.236^{\mathrm{bc}}$ & 0.92 & $0.87 \pm 0.005^{j}$ & 1.18 & $5.72 \pm 0.017^{c}$ & 1.00 \\
\hline$(\mathrm{LCT} T)+.\mathrm{RT}$ & $3.91 \pm 0.017^{\mathrm{e}}$ & 0.83 & $7.52 \pm 0.130^{\mathrm{bc}}$ & 0.88 & $0.92 \pm 0.011^{\mathrm{i}}$ & 1.24 & $5.79 \pm 0.097^{c}$ & 1.02 \\
\hline (LCH F.) & $4.19 \pm 0.025^{\mathrm{d}}$ & - & $5.91 \pm 0.104^{d}$ & - & $1.22 \pm 0.017 \mathrm{e}$ & - & $8.12 \pm 0.213^{\mathrm{a}}$ & - \\
\hline (LCT F.) + Vit.E & $4.41 \pm 0.015^{c}$ & 0.93 & $7.78 \pm 0.128^{b c}$ & 0.91 & $0.93 \pm 0.005^{i}$ & 1.26 & $5.86 \pm 0.197^{c}$ & 1.03 \\
\hline (LCT F.) + RT & $3.82 \pm 0.011^{\mathrm{e}}$ & 0.81 & $7.49 \pm 0.089 \mathrm{bc}$ & 0.87 & $0.98 \pm 0.005^{h}$ & 1.32 & $5.81 \pm 0.011^{\mathrm{c}}$ & 1.02 \\
\hline
\end{tabular}

\subsection{Effects of LCT on SOD, CAT, GPx, GR, GST activities and LPO level in serum of male rats}

Results of toxic effects of LCT (T or F) and the protective effects of Vit E or RT on serum SOD, CAT, GPx, GR and GST activites and LPO level were recorded in Tables 3\&4. These parameters in Vit E- or Rutin - treated rats did not differ from those of control group. Serum SOD , CAT, GPx, GR, GST activites were significantly decreased in LCT-treated rats , while serum LPO level was significantly ( $\leq 0.05$ ) increased as compared with control group . Co-administration of Vit $\mathrm{E}$ and Rutin caused significant $(\mathrm{P} \leq 0.05)$ increase in the activity of SOD , CAT , GPx, GR, GST and decrease in the level of LPO as compared with control (Tables 3 and 4). In all of the previous results, formulated $\lambda$-Cyhalothrin (LCT. F) had slightly more toxic effect than the technical LCT, while their combination with Vit.E or Rutin reduced significantly their toxic effects.

Table 3 Activities of some biomarkers related to oxidative stress (SOD, CAT, GPx) in male rats induced by lambdacyhalothrin (LCT T.; LCT F.); and the ameliorative effect of Vit E and RT supplementation.

\begin{tabular}{|c|c|c|c|c|c|c|}
\hline \multirow{2}{*}{ Treatments } & \multicolumn{2}{|c|}{$\begin{array}{l}\text { Superoxide dismutase } \\
\text { (SOD) }(\mu \mathrm{mol} / \mathrm{min} / \mathrm{ml})\end{array}$} & \multicolumn{2}{|c|}{$\begin{array}{l}\text { Catalase }(\mathrm{CAT}) \\
(\mu \mathrm{mol} / \mathrm{min} / \mathrm{ml})\end{array}$} & \multicolumn{2}{|c|}{$\begin{array}{l}\text { Glutathione peroxidase } \\
(G P x)(\mu \mathrm{mol} / \mathrm{min} / \mathrm{ml})\end{array}$} \\
\hline & Mean \pm SE & A.I.* & Mean \pm SE & A.I.* & Mean \pm SE & A.I. \\
\hline Control & $104.33 \pm 0.881^{b}$ & - & $0.53 \pm 0.012^{\mathrm{ab}}$ & - & $0.87 \pm 0.015^{\mathrm{a}}$ & - \\
\hline Vitamin (E) & $109.61 \pm 0.743^{a}$ & - & $0.54 \pm 0.005^{\mathrm{a}}$ & - & $0.91 \pm 0.028^{\mathrm{a}}$ & - \\
\hline RT & $105.18 \pm 1.742^{b}$ & - & $0.53 \pm 0.026^{\mathrm{ab}}$ & - & $0.89 \pm 0.010^{\mathrm{a}}$ & - \\
\hline (LCT T.) & $73.36 \pm 0.633^{f}$ & - & $0.38 \pm 0.015^{\mathrm{d}}$ & - & $0.69 \pm 0.024^{\mathrm{d}}$ & - \\
\hline (LCT T.) + Vit.E & $101.80 \pm 0.61^{c}$ & 0.98 & $0.52 \pm 0.028^{\mathrm{abc}}$ & 0.98 & $0.86 \pm 0.010^{\mathrm{a}}$ & 0.99 \\
\hline (LCT T.) + RT & $96.70 \pm 1.173^{\mathrm{d}}$ & 0.93 & $0.50 \pm 0.017 \mathrm{abc}$ & 0.94 & $0.76 \pm 0.012^{\mathrm{bc}}$ & 0.87 \\
\hline (LCT F.) & $72.33 \pm 0.333^{f}$ & - & $0.36 \pm 0.003^{\mathrm{d}}$ & - & $0.69 \pm 0.015^{\mathrm{d}}$ & - \\
\hline (LCT F.) + Vit.E & $99.76 \pm 0.233^{c}$ & 0.96 & $0.51 \pm 0.011^{\mathrm{abc}}$ & 0.96 & $0.86 \pm 0.004^{\mathrm{a}}$ & 0.99 \\
\hline (LCT F.) + RT & $94.73 \pm 0.371^{\mathrm{de}}$ & 0.91 & $0.48 \pm 0.011^{\mathrm{abc}}$ & 0.91 & $0.78 \pm 0.005^{b c}$ & 0.90 \\
\hline
\end{tabular}


Table 4 Levels of some biomarkers related to oxidative stress (GR, GST, LPO) in male rats induced by $\lambda$-Cyhalothrin, (LCT T.); (LCT F.) and the ameliorative effect of Vit E and RT supplementation.

\begin{tabular}{|c|c|c|c|c|c|c|}
\hline \multirow[t]{2}{*}{ Treatments } & \multicolumn{2}{|c|}{$\begin{array}{l}\text { Glutathione reductase } \\
(\mathrm{nmol} / \mathrm{min} / \mathrm{ml})(\mathrm{GR})\end{array}$} & \multicolumn{2}{|c|}{$\begin{array}{l}\text { Glutathione-S- } \\
\text { transferase } \\
(\mu \mathrm{mol} / \mathrm{min} / \mathrm{ml})(\mathrm{GST})\end{array}$} & \multicolumn{2}{|c|}{$\begin{array}{l}\text { lipid } \quad \text { peroxidation } \\
\text { (LPO) }(\mathrm{nmol} / \mathrm{ml})\end{array}$} \\
\hline & Mean \pm SE & A.I.* & Mean \pm SE & A.I.* & Mean \pm SE & A.I.* \\
\hline Control & $83.86 \pm 0.953^{\mathrm{a}}$ & - & $1.63 \pm 0.028^{a}$ & - & $1.49 \pm 0.025^{\mathrm{d}}$ & - \\
\hline Vitamin (E) & $81.87 \pm 1.850^{a}$ & - & $1.62 \pm 0.015^{\mathrm{a}}$ & - & $1.51 \pm 0.015^{\mathrm{cd}}$ & - \\
\hline RT & $84.20 \pm 2.795^{\mathrm{a}}$ & - & $1.64 \pm 0.023^{\mathrm{a}}$ & - & $1.48 \pm 0.023^{\mathrm{d}}$ & - \\
\hline (LCT T.) & $50.61 \pm 1.141^{b}$ & - & $1.14 \pm 0.005^{\mathrm{i}}$ & - & $2.45 \pm 0.023^{b}$ & - \\
\hline (LCT T.) + Vit.E & $79.17 \pm 1.678^{a}$ & 0.94 & $1.56 \pm 0.015^{b}$ & 0.96 & $1.58 \pm 0.017^{\mathrm{cd}}$ & 1.10 \\
\hline (LCT T.) + Rutin & $82.78 \pm 1.060^{\mathrm{a}}$ & 0.99 & $1.49 \pm 0.020^{\mathrm{cd}}$ & 0.91 & $1.50 \pm 0.011^{\mathrm{cd}}$ & 1.01 \\
\hline (LCT F.) & $48.96 \pm 0.844^{b}$ & - & $1.12 \pm 0.003^{\mathrm{i}}$ & - & $2.41 \pm 0.015^{b}$ & - \\
\hline (LCT F.) + Vit.E & $78.96 \pm 0.584^{\mathrm{a}}$ & 0.94 & $1.50 \pm 0.011^{b c}$ & 0.95 & $1.54 \pm 0.015^{\mathrm{cd}}$ & 1.03 \\
\hline (LCT F.) + Rutin & $81.12 \pm 1.617^{a}$ & 0.98 & $1.48 \pm 0.005^{\mathrm{d}}$ & 0.91 & $1.56 \pm 0.005^{c d}$ & 1.05 \\
\hline
\end{tabular}

The effect of Vit.E or RT administration on ameliorating the toxicity induced by LCT in rats was expressed in terms of the "Amelioration Index" (A.I.). As shown in the previous results, the AI for LPO equaled 1.1 (1.01) and 1.03 (1.05), respectively, in the treatments of Vit.E (or RT) with LCT T. and LCT F. On the other hand, A.I. values for GR equaled 0.94 (0.99); 0.94 (0.98), respectively. In general the AI values recorded greater than 1.0 for some biochemical parameters and less than 1.0 for others. The highest AI value (1.39) was entitled to ALT for (LCT F. + RT) treatment, while the lowest AI value (0.81) was entitled to albumin for (LCT F. + RT) treatment.

\section{Discussion}

In the present study, there was no significant changes in the activity of the biomarkers enzymes in the serum of Rutin or Vit E - treated rats as compared to control, while exposure of male rats to sub-lethal dose of lambda-cyhalothrin caused an oxidative stress in liver and kidney of the rat as evidenced by significant elevation of ALT, AST, ALP, LDH, uric acid, creatinine and significant decrease in total protein, and albumin levels in serum of treated rats. Moreover, serum SOD , CAT, GPx, GR , GST activities were significantly decreased in LCT-treated rats, while serum LPO level was significantly $(\mathrm{P} \leq 0.05)$ increased as compared with control group. This perturbation in these enzymes may be indication to liver and kidney damage or due to alterations in the permeability of cell membrane and increased synthesis or decreased catabolism of amino transferases as reported by [29; 30; 31]. The impairment of antioxidant enzyme activities, clearly indicated that $\lambda$-cyhalothrin had the potency to cause oxidative damage. The increase in the level of lipid peroxidase (LPO) and observable reduction in GSH levels in the serum of treated rats is an early consequence of oxidative stress as expressed by increasing LPO. Antioxidant enzymes present an impressive array of defense mechanisms that are effective in maintaining ROS under adequate concentrations. Among these antioxidant enzymes are SOD, CAT, and GST that work in synergy with non-enzymatic antioxidants to neutralize free radicals and counteract oxidative cellular damage and small deviations in the physiological concentrations of these antioxidant enzymes may have a dramatic effect on the resistance of cellular lipids, proteins and DNA to oxidative damage [32]. Furthermore, alteration in GST activity has been recorded in the current investigation. Considering that glutathione- S-transferases are detoxifying enzymes that catalyze the conjugation of a variety of electrophilic substrates to the thiol group of GSH, producing less toxic forms [33]. LPO is known to disturb the integrity of cellular membranes, leading to the leakage of cytoplasmic enzymes [34]. Perturbations in such enzymes may be due to alterations in the permeability of cell membrane and increased synthesis or decreased catabolism of aminotransferases [35; 30].

The present results demonstrated that $\lambda$-cyhalothrin caused significant reduction in the activity of CAT and SOD. Two mechanisms might play a role in this decrease as reported by [36; 37; 38]. The first involved consumption during the break down of free radicals and the high level of $\mathrm{H} 2 \mathrm{O} 2$ or the inhibition of the enzyme by these radicals, while the second involved the direct inhibition of SOD and CAT by $\lambda$-cyhalothrin, as also demonstrated for other pyrethroids. Reduction in GST activities in rat is in consistence with the findings of [39] who reported a time- dependent change in GST activity 
in the rat liver tissues following its exposure to a mixture of organophosphate and pyrethroid insecticides .The decrease in GST activity in the present study may be due to the fact that $\lambda$-cyhalothrin consumes GSH through a detoxification reaction and/or that GST catalyzes this reaction [33]. In consistence with the findings of [40; 38; 41] who reported that pyrethroids exposure could induce oxidative stress in vivo and in vitro as indicated by elevated free radicals concentration and decreased GSH content, which would further induced lipid peroxidation, initiated free radicals damage to hepatocellular membrane and led to liver injury.

Co-treatment with rutin and Vitamin E allowed recovering some of the enzymatic activities lost by $\lambda$-cyhalothrin treatment near to their normal levels. The beneficial effects of rutin or vitamin $\mathrm{E}$ can be attributed to their antioxidant effects as scavengers of oxygen-free radicals which are toxic byproducts of many metabolic processes. The beneficial effect of Vit.E is mostly due to its antioxidant properties. Vitamin E protects critical cellular structures against damage caused by oxygen-free radicals and reactive products of lipid peroxidation. Vitamin E, as a lipid soluble antioxidant, plays a major protective role against oxidative stress and prevents the production of lipid peroxides by scavenging free radicals which are toxic byproducts of many metabolic processes in biological membranes [42]. Moreover, VE is essential in maintaining the physiological integrity of testis, epididymis and accessory glands [43]. The ameliorating effect of VE against the toxicity of lambda-cyhalothrin on semen quality may be due to their role as antioxidant through the reduction in LPO potential [44]. Rutin is electron donor, and its derivatives indicate that they are potential antioxidants [45]. It seems that the protective effect of rutin may be at least, in part, due to suppression of ROS generation because it exhibited antioxidant effect in different studies [46]. Thus, results showed that co-treatment of rats with rutin and $\lambda$-cyhalothrin for 30 days decreased $\lambda$-cyhalothrin toxicity. Many authors reported that rutin has several pharmacological properties, including antioxidant, anticarcinogenic, cytoprotective, vasoprotective, cardioprotective and neuroprotective activities [47; 48]. Rutin has beneficial effects on hypoxic, glutamate and oxidative stress on retinal ganglion cell. It appears that the sugar side chain of flavonoids may be important for neuroprotective activities [49]. Also, the present study showed that induction of lyposomal enzymes was associated with a decrease in serum protein thiol level. Early study [50] confirms our finding and concludes that ROS can induce oxidation of critical sulfhydryl (SH) groups in protein, which will alter cellular integrity and function. The antioxidant properties of RT and vitamin E scavenge the oxygen free radicals and preservation of cellular viability serving secondarily to preserve lysosomes, thereby retaining near normal functioning of the lysosomes. Indeed, cathepsin D is lysosomal proteases possibly involved in autophagic of discrete areas of cytoplasm, and mitochondria proteins (Zak et al., 1976). The antioxidant activity of RT and vitamin E stopped this reaction by iron chelating activity. According to our results, pretreatment with Vitamin E or Rutin have shown abilities to preserve the activity of antioxidant enzymes and lysosomal membrane which may be referred to its role in modulating the levels of $\mathrm{H} 2 \mathrm{O} 2$ and 02 . Furthermore, the contents of such substances have been suggested to induce the de novo synthesis of antioxidant enzymes by acting as several loci in the metabolic pathway. In the current study revealed that the efficiency of Vit.E or RT to alleviate the oxidative stress exerted by exposure to the technical and formulated LCT resulted in amelioration indices (AI) around 1. Values of AI exceeding 1.0 may refer to either better improvement or negligible experimental errors. The obtained results are supported by those obtained in previously published investigations (Mansour and Gamet-Payrastre, 2016; Mansour et al., 2017).

\section{Conclusion}

The present study has shown that oxidative stress plays an essential role in lambada-cyhalothrin mediated injury and the co-administration of rutin or Vitamin E ameliorated the injury through its free radical scavenging effect. Therefore, the administration of Rutin or Vit.E may be of value to farmers and other workers who are frequently exposed to pyrethroid insecticides (e.g. lambda-cyhalothrin) to reduce their expected injury.

\section{Compliance with ethical standards}

\section{Acknowledgments}

The authors thank Prof. Mohamed H. Belal Prof. of Pesticides, Fac. of Agric., Cairo Univ. and the late Prof. Mamdouh A. Marzouk, Fac. of Agric. Damanhur Univ. for their kind support they gave to this study.

\section{Disclosure of conflict of interest}

The authors declare no conflict of interest. 


\section{Statement of ethical approval}

The experimental work on rats was performed with the approval of the Animal Care and Experimental Committee, Fac. of Agriculture, Damanhur University, Egypt and according to the guidance for the care and use of laboratory animals. [12]

\section{References}

[1] Giray B, Gurbay A and Hincal F. (2001). Cypermethrin-induced oxidative stress in rat brain and liver is prevented by vitamin E or allopurinol. Toxicol Lett, 118, 139-146.

[2] El-Demerdash FM, Yousef MI, Kedwany FS and Baghdadi HH. (2004). Role of a-tocopherol and b-carotene in ameliorating the fenvalerate induced changes in oxidative stress, hemato-biochemical parameters and semen quality of male rats. J. Environ. Sci. Health, B39, 443-459.

[3] Prasanthi K, Muralidhara and Rajini PS. (2005). Fenvalerate-induced oxidative damage in rat tissues and its attenuation by dietary sesame oil. Food Chem. Toxicol, 43, 299-306.

[4] Yousef M, Awad T and Mohamed E. (2006). Deltamethrin-induced oxidative damage and biochemical alterations in rat and its attenuation by Vitamin E. Toxicology, 227, 240-247.

[5] Nice D. (1997). Antioxidant based nutraceuticals. In: YalpaniM (Edn), New Technologies for Healthy Foods and Nutraceuticals. Science Publishers, Shrewsbury, 105-123.

[6] Deschner EE, Ruperto J, Wong G and Newmark HL. (1991). Quercetin and rutin as inhibitors of azoxymethanolinduced colonic neoplasia. Carcinogenesis; 12, 1193-1196.

[7] Janbaz KH, Saeed SA and Gilani AH. (2002). Protective effect of rutin on paracetamol and CCl4 induced hepatotoxicity in rodents. Fitoterapia, 73, 557-563.

[8] Yin Z, Wang J, Gu X, Gu H and Wen y. (2012). Antioxidant and a-glucosidase inhibitory activity of red raspberry (Harry waters) fruits in vitro. Afr J Pharm Pharmacol, 6(45), 3118-3123.

[9] Shalaby MA, HY El-Zorba, Gihan and Kamel M. (2004). Effect of alphatocopherol and simvastatin on male fertility in hypercholesterolemic rats. Pharmacol. Res, 50(2), 137-142.

[10] Ramachandran V and Raja B. (2010). Protective effects of vitamin E and syringic acid against acetaminophen induced hepatic damage in albino rats. J. Basic Clin. Physiol. Pharmacol, 21(4), 369-385.

[11] Iranloye BO and Oludare GO. (2011). Garlic and vitamin E provides antioxidant defense in tissues of female rats treated with nicotine. Nigerian J. Physiol. Sci, 26, 103-107.

[12] NRC. (1996). Guide for the Care and Use of Laboratory Animals, National Research Council, Academic Press, Washington, DC, USA, 1996; p. 12.

[13] Anadon A, M Mart'inez, MA Mart'inez, MJ D'iaz and MR Mart'ınez-Larra naga. (2006). Toxicokinetics of lambdacyhalothrin in rats. Toxicol. Letters, 165, 47-56.

[14] Caria H, T Chaveca, A Laires and J Rueff. (1995). Genotoxicity of quercetin in the micronucleus assay in mouse bone marrow erythrocytes, human lymphocytes, V79 cell line and identification of kinetochore-containing (CREST staining) micronuclei in human lymphocytes. Mutat. Res, 343, 85-94.

[15] Ohkawa H, Ohishi N and Yagi K. (1979). Assay for lipid peroxides in animal tissues by thiobarbituric acid reaction. Anal Biochem, 95, 351-358.

[16] Ellman GL. (1959). Tissue sulfhydryl groups. Arch Biochem Biophys, 82, 70-77.

[17] Misra HP and Fridovich I. (1972). The role of superoxide anion in the autoxidation of epinephrine and a simple assay for superoxide dismutase. J Biol Chem, 247, 3170-3175.

[18] Aebi H. (1984). Catalase in vitro, 3rd ed. Methods in Enzymology, Vol. 105. Philadelphia: Lippincott-Raven Publishers, 121-126.

[19] Paglia and Valentine. (1967). J. Lab. Clin. Med., 70, 158-169.

[20] Habig WH, Pabst MJ and Jakoby WB. (1974). Glutathione S-transferases. The first enzymatic step in mercapturic acid formation. J Biol Chem, 249, 7130-7139. 
[21] Hafeman DG, Sunde RA and Hoekstra WG. (1974). Effect of dietary selenium on erythrocyte and liver glutathione peroxidase in the rat. J Nutr, 104, 580-587.

[22] Principato GB, Asia MC, Talesa V, Rosi G and Giovannini E. (1985). Characterization of the soluble alkaline phosphatase from hepatopancreas of Squilla mantis L. Comp Biochem Physiol B, 985, 801-804.

[23] Reitman S and Frankel S. (1957). A method of assaying liver enzymes in human serum. American Journal of Clinical Pathology, 28, 56 - 58.

[24] Cabaud PC and Wroblewski F. (1958). Calorimetric measurement of lactate dehydrogenase activity of body fluids. J Clin Pathol, 30, 234-236.

[25] Lowry OH, Rosebrough NJ, Farr AL and Randall RJ. (1951). Protein Measurement with the Folin phenol reagent. J Biol Chem, 193, 269-275.

[26] Morgenstern S, Flor RV, Kaufman JH and Klein B. (1966). The automated determination of serum uric acid. Clin. Chem, 12, 748-766.

[27] Mitchell RJ. (1973). Improved method for specific determination of creatinine in serum and urine. Clin. Chem, 19, $408-410$.

[28] Mansour SA and Gamet-Payrastre L. (2016). Ameliorative effect of vitamin E to mouse dams and their pups following exposure of mothers to chlorpyrifos during gestation and lactation periods.Toxicol. Ind. Health, 32, 1179-1196.

[29] El-Shenawy NS, El-Salmy F, Al-Eisa RA and El-Ahmary B. (2010). Amelioratory effect of vitamin E on organophosphorus insecticide diazinon-induced oxidative stress in mice liver.Pest Biochem Physiol, 96, 101107.

[30] Kalender S et al. (2005). Diazinon-induced hepatotoxicity and protective effect of vitamin E on some biochemical indices and ultra-structural changes. Toxicology, 211, 197-206.

[31] Abbassy MA and ATH Mossa. (2012). Haemato-biochemical effects of formulated and technical cypermethrin and deltamethrin insecticides in male rats. J. Pharmacol. Toxicol, 7, 312-321.

[32] Bal R, Naziro_glu M, T€urk G, Yilmaz €O, Kulo_glu T, Etem E and Baydas G. (2012). Insecticide imidacloprid induces morphological and DNA damage through oxidative toxicity on the reproductive organs of developing male rats. Cell Biochem Funct, 30, 492-499.

[33] Ranjbar A, Solhi H, Mashayekhi F, Susanbdi J, Rezaie A and Abdollahi M. (2005). Oxidative stress in acute human poisoning with organophosphorus insecticides; a case control study. Environ Toxicol Pharmacol, 20, 88-91.

[34] Bagchi D, Bagchi M, Hassoun EA and Stohs SJ. (1995). In vitro and in vivo generation of reactive oxygen species, DNA damage and lactate dehydrogenase leakage by selected pesticides. Toxicology, 104, 129-140.

[35] Ali BJ, Hoda MN and Fatma M. El-Demerdash (2013). Selenium Modulates b-Cyfluthrin-Induced Liver Oxidative Toxicity in Rats. Environmental Toxicology Wiley Online Library (wileyonlinelibrary.com).

[36] Eraslan G, Kanbur M, Silici S, Altinordulu S and Karaback M. (2008). Effects of cypermethrin on some biochemical changes in rats, the protective role of propolis. Exp Anim, 57, 453-460.

[37] Eraslan G, Saygi S, Essiz D, Aksoy A, Gul H and Macit E. (2007). Evaluation of aspect of some oxidative stress parameters using vitamin $\mathrm{E}$, proanthocyanidin and $\mathrm{N}$-acetylcysteine against exposure to cyfluthrin in mice. Pest Biochem Physiol, 88, 43-49.

[38] El-Demerdash FM. (2007). Lambda-cyhalothrin-induced changes in oxidative stress biomarkers in rabbit erythrocytes and alleviation effect of some antioxidants. Toxicol In Vitro, 21, 392-397.

[39] El-Demerdash FM. (2011). Oxidative stress and hepatotoxicity induced by synthetic pyrethroidsorganophosphate insecticides mixture in rat. J Environ Sci Health C, 29, 145-158.

[40] Nasuti C, Cantalamessa F, Falcioni G and Gabbianelli R. (2003). Different effects of type I and type II pyrethroids on erythrocyte plasma membrane properties and enzymatic activity in rats. Toxicology, 191, 233-244.

[41] Fetoui H, E Garoui and N Zeghal. (2009). Lambda-cyhalothrin-induced biochemical and histopathological changes in the liver of rats: Ameliorative effect of ascorbic acid. Experimental and Toxicologic Pathology, 61, 189-196.

[42] Oda SS and El-Maddawy Z. (2012). Protective effect of vitamin E and selenium combination on deltamethrininduced reproductive toxicity in male rats. Experimental and Toxicologic Pathology, 64, 813-819. 
[43] Cerolini S, Zaniboni L, Maldjian A and Gliozzi T. (2006). Effect of docosa hexaenoic acid and alpha tocopherol enrichment in chicken sperm on semen quality, sperm lipid composition and susceptibility to peroxidation. Theriogenology, 66, 877-886.

[44] Yousef M. (2010). Vitamin E modulates reproductive toxicity of pyrethroid lambda-cyhalothrin in male rabbits. Food and Chemical Toxicology, 48, 1152-1159.

[45] Manivannan C, Sundaram KM, Renganathan R and Sundararaman M. (2012). Investigations on photoinduced interaction of 9-aminoacridine with certain catechols and rutin. J Fluoresc, 22, 1113-1125.

[46] Becker EM, Ntouma G and Skibsted LH. (2007). Synergism between and antagonism between quercetin and other chain-breaking antioxidants in lipid systems of increasing structural organization. Food Chem, 103, 1288-1296.

[47] Javed H, Khan MM, Ahmad A, Vaibhav K, Ahmad ME, Khan A, Ashafaq M, Islam F, Siddiqui MS, Safhi MM and Islam F.(2012). Rutin prevents cognitive impairments by ameliorating oxidative stress and neuro inflammation in rat model of sporadic dementia of Alzheimer type. Neuroscience, 17, 340-352.

[48] Yang YC, Lin HY, Su KY, Chen CH, Yu YL, Lin CC, Yu SL, 40- Yan HY, Su KJ and Chen YL. (2012).Rutin, a flavonoid that is a main component of Saussurea involucrata, attenuates the senescence effect in D-Galactose aging mouse model. Evid Based Complement Alternat Med, 980276.

[49] Nakayama T, Yamada M, Osawa T and Kawakishi S. (1993). Suppression of active oxygen-induced cytotoxicity by flavonoids. Biochem Pharmacol, 45, 265-267.

[50] Teimouri F, Amirkabirian N, Esmaily H, Mohammadirad A, Ali ahmadi A and Abdollahi M. (2006). Alteration of hepatic cells glucose metabolism as a non-cholinergic detoxification mechanism in counteracting diazinon induced oxidative stress. Hum.Exp.Toxicol, 25, 697-703.

[51] Zak R, Martin AF, Reddy MK and Rabinowitz M. (1976). Control of protein balance in hypertrophied cardiac muscle. Circ Res; 38 (5 supp1), 1145.

[52] Mansour SA, Abbassy MA and Shaldam HA. (2017). Zinc ameliorate oxidative stress and hormonal disturbance induced by methomyl, abamectin and their mixture in male rats. Toxics, 5(37).

\section{How to cite this article}

Abbassy MA, Nasr HM and Mansy AS. (2020). Rutin and Vitamin E alleviate oxidative stress and hepatic-renal injury induced by technical and formulated Lambda-cyhalothrin in adult rats. GSC Biological and Pharmaceutical Sciences, $12(1), 31-40$. 